\title{
IS THERE ANY DIFFERENCE IN FITNESS PROFILES AMONG THE CROATIAN BASKETBALL PLAYERS? POSITION SPECIFIC ANALYSIS
}

\author{
Luka Milanović, Igor Jukić, Marin Dadić, Vlatko Vučetić, and Davor Šentija \\ University of Zagreb, Faculty of Kinesiology, Croatia
}

Original scientific article

DOI: $10.26582 / \mathrm{k} .51 .2 .17$

\begin{abstract}
:
The aim of the study was to establish possible differences in both aerobic and anaerobic fitness parameters among different positions (point guards, shooting guards, small forwards, power forwards, and centers) in basketball. Based on previous research on certain differences among play positions in basketball, aerobic and anaerobic fitness capacity values of basketballers in different positions were analyzed. Seventy adult basketball players (age 24.37 \pm 4.05 years) from the Croatian Division 1 league were classified as point guards $(n=20)$, shooting guards and small forwards $(n=26)$, and power forwards and centers $(n=24)$. Six variables of cardiopulmonary function were obtained using spirometry and spiroergometry test. Regarding aerobic abilities, a significant difference among the three positions was found only in the $\mathrm{VO}_{2 \max }$ parameters $(\mathrm{p}=.00)$ in favor of power forwards and centers $(5.55 \pm 0.6 \mathrm{l} / \mathrm{min})$ when compared to point guards $(4.7 \pm 0.6 \mathrm{~L} / \mathrm{min})$ and shooting guards and small forwards $(5.01 \pm 0.6 \mathrm{l} / \mathrm{min})$. No significant difference was found in the Croatian basketballers' anaerobic capacity parameters among the three different play positions.
\end{abstract}

Key words: basketball, men, aerobic abilities, anaerobic capacity, spiroergometry, progressive all-out treadmill test

\section{Introduction}

The game of basketball is characterized by numerous short, but high-intensity actions executed in different planes (Cuzzolin, 2005). When considering all types of intensity during a match, basketball players spend $15.5 \%$ time standing, $14.4 \%$ walking, $11.6 \%$ jogging, $10.4 \%$ running, 5.3\% sprinting, and $42.8 \%$ of match time in basketballspecific activities (i.e. defensive stance, shuffling, cutting, jumping, etc.). Furthermore, much information on work intensity in basketball is presented through the analysis of the time of offense play, where the positional offense play takes 7-18 seconds (75\% of all offensive time), while the transitional offense play lasts only 4-6 seconds (Abdelkrim, Fazaa, \& El Ati 2007; McInnes, Carlson, Jones, \& McKenna, 1995; Read, et al., 2014; Tavares \& Gomes, 2003). Several studies in basketball have confirmed the players' average heart rate (HR) of 165-170 bpm (Abdelkrim, Chaouachi, Chamari, Chtara, \& Castagna, 2010). As regards physiological demands of the game expressed in HR zones, Abdelkrim et al. (2010) state that players spend $19.3 \%$ of the total time in a maximal-intensity zone, $56 \%$ in a high-intensity, $17.3 \%$ in a moderate-intensity, and $7.4 \%$ in a low-intensity zone.
Considering the demands of different basketball positions, Abdelkrim et al. (2007) found the significant differences in high-intensity actions between guards and forwards (17.1\% and 16.6\%, respectively) to centers $(14.7 \%)$.

When comparing the number of different actions during a game, Abdelkrim et al. (2007) state that there is no significant difference between forwards and centers (1022 \pm 45 and $1026 \pm 27$, respectively), while the guards differ significantly compared to forwards and centers $(1103 \pm 32 ; \mathrm{p}<.01)$. Furthermore, Cuzzolin (2005) has confirmed the difference among play positions in the number of pivoting moves per five minutes of a game where point guards perform 40 , shooting guards and forwards 35 , and centers 30 pivoting moves.

From the physiological point of view, the studies conducted on basketball players' performance during games showed different values of the blood lactate concentration. The levels vary from $4.2 \pm 1.3$ and 5.7 \pm 1.2 (Abdelkrim, et al., 2010) to 6.8 $\pm 2.8 \mathrm{mmol} / \mathrm{L}$ (McInnes, et al., 1995). The highest individual level of the blood lactate concentration registered was $13.2 \mathrm{mmol} / \mathrm{L}$ (McInnes, et al., 1995). As in other team sports, the blood lactate concentration among basketball players is significantly 
higher at the end of a game, which is explained by a lower lactate tolerance during a higher fatigue state (McInnes, et al., 1995).

Based on previous research on play positions (Cormery, Marcil \& Bouvard, 2008; Ostojić, Mazić $\&$ Đikić, 2006), their anthropometric characteristics, roles and game performance in basketball, we presumed certain statistical differences might be established in players' aerobic and anaerobic fitness indicators among the three basic positions. The aim of the study was to establish possible differences in both aerobic and anaerobic parameters among different play positions (point guards; shooting guards and small forwards; and power forwards and centers) in basketball. The main objective of this study was to analyze aerobic and anaerobic fitness indicators of top basketball players in different play positions. Findings of the study examining the differences between players in different team sports can be used to improve the definition of the criteria for the selection of potential top basketball players as well as training process planning, programming and control.

\section{Methods}

\section{Participants}

The study was conducted in 2011 with the Croatian Division I basketball players who were tested at the Faculty of Kinesiology, University of Zagreb. The sample comprised 70 basketball players (age $24.37 \pm 4.05$ years) within their regular pre-season training regimen, out of which 20 point guards (age $23.46 \pm 4.21$ years); 26 shooting guards and small forwards (age $25.38 \pm 4.20$ years); and 24 power forwards and centers (age 23.74 \pm 3.48 years). All pertained to the highest quality level of their sport in Croatia, some even being members of respective national teams. The same testing protocol was applied to every participant. The study was approved by the Ethical Committee of the Faculty of Kinesiology, Zagreb, Croatia, according to the recommendations of the revised Declaration of Helsinki (2008).

\section{Variables}

For the diagnostics of players' metabolic efficiency, six variables divided into two groups, representing the parameters of aerobic abilities and anaerobic capacities, were used.

For the assessment of aerobic ability, the following variables were used:

1. Maximum absolute oxygen uptake $\left(\mathrm{VO}_{2 \max } ; 1 /\right.$ $\min )$

2. Maximum relative oxygen uptake $\left(\mathrm{RVO}_{2 \max }\right.$; $\mathrm{ml} / \mathrm{kg} / \mathrm{min}$ )

3. Maximum running speed on the treadmill $\left(\mathrm{v}_{\max }\right.$; $\mathrm{km} / \mathrm{h}$ )
4. Running speed at the ventilation anaerobic threshold $\left(\mathrm{v}_{\mathrm{AnT}} ; \mathrm{km} / \mathrm{h}\right)$

For the assessment of anaerobic capacity, the following variables were used:

1. Time in the anaerobic zone $\left(\mathrm{t}_{\mathrm{an}} ; \mathrm{s}\right)$

2. Distance covered in the anaerobic zone $\left(\mathrm{ds}_{\mathrm{tot}} ; \mathrm{m}\right)$. The measurement procedures were conducted at the Sports Diagnostic Centre, University of Zagreb, Faculty of Kinesiology. Variables estimating aerobic and anaerobic capacities were obtained with the standardized test protocol. All parameters were analyzed after the increment running treadmill test (Cosmed, Quark b2, Italy). Each participant was first familiarized with the goals and protocol of the all-out treadmill testing. Afterwards, he put on a size-tailored facemask, and a band for HR telemetric monitoring was fixed on his chest (Polar Electro OY CE 0537, Finland). The utilized measuring instruments (Cosmed, Quark $\mathrm{b}^{2}$ "breath by breath" spiroergometer, treadmill Technogym - Runrace Competition HC1200, and telemetric heart rate monitor - Polar Electro OY CE 0537) provided a direct on-line monitoring and analysis of ventilation and metabolic parameters. After the phase of 1-minute quiet standing, the test started with a 2-minute walking at the speed of 3 $\mathrm{km} / \mathrm{h}$. After that, the treadmill speed was increased by $1-\mathrm{km} / \mathrm{h}$ every minute. The treadmill inclination of $1.5 \%$ remained constant. The subjects walked during the first four load stages (up to $6-\mathrm{km} / \mathrm{h}$ ), then started to run (speed of 7-km/h and above). When the test was completed with a volitional cessation, the maximum speed was established by the last load level the subject had managed to run through for half a minute. During the recovery phase, the subject continued to walk at $5-\mathrm{km} / \mathrm{h}$ speed while the spiroergometric parameters were monitored.

\section{Data analysis}

The results were analyzed using the software package Statistica for Windows, version 10.0.

Basic descriptive parameters were computed for the fitness profiles creation of basketball players in different play positions. Univariate analysis of variance (ANOVA) with the Bonferroni post-hoc test was used for the determination of differences among the basketball players in different play positions in the variables assessing their physical fitness.

The level of significance was set at $\mathrm{p}<.05$.

\section{Results}

Table 1 presents the descriptive parameters of aerobic and anaerobic capacities of basketball players. Based on the scores presented, the Croatian basketball players demonstrated, in general, an appropriate level of energy supplying abilities with average values of maximal oxygen uptake of 5.11 $1 / \mathrm{min}$, relative maximal oxygen uptake of $55.5 \mathrm{ml} /$ 
$\mathrm{kg} / \mathrm{min}$ and $\mathrm{v}_{\max }$ of $17.7 \mathrm{~km} / \mathrm{h}$. Analysis of skewness and kurtosis showed a normal distribution of data.

Table 2 displays the basic descriptive parameters used for the assessment of the energy supplying abilities separately for point guards, shooting guards/small forwards, and power forwards/centers in basketball. Average $\mathrm{RVO}_{2 \max }$ values for point guards, shooting guards/small forwards and power forwards/centers corresponded to the results of the studies conducted by Latin et al. (1994), Sallet et al. (2005) and Abdelkrim et al. (2010).

\section{Analysis of differences in the variables assessing aerobic abilities}

Table 3 and Figure 1 show the results of average maximum oxygen uptake for point guards $(4.7 \pm 0.61 /$ $\mathrm{min})$; shooting guards and small forwards $(5.01 \pm 0.6$

Table 1. Descriptive values of aerobic and anaerobic parameters of the total sample

\begin{tabular}{|c|c|c|c|c|c|c|c|c|c|}
\hline Test & Valid N & Mean & Minimum & Maximum & Range & Variance & Std.Dev. & Skewness & Kurtosis \\
\hline $\mathrm{VO}_{2 \max }(1 / \min )$ & 70 & 5.11 & 3.92 & 6.82 & 2.90 & 0.46 & 0.68 & 0.03 & -0.54 \\
\hline $\mathrm{RVO}_{2 \max }(\mathrm{ml} / \mathrm{kg} / \mathrm{min})$ & 70 & 55.46 & 44.90 & 65.20 & 20.30 & 23.02 & 4.80 & 0.25 & -0.57 \\
\hline $\mathrm{v}_{\max }(\mathrm{km} / \mathrm{h})$ & 70 & 17.70 & 14.00 & 21.00 & 7.00 & 2.16 & 1.47 & -0.06 & -0.56 \\
\hline $\mathrm{v}_{\mathrm{AnT}}(\mathrm{km} / \mathrm{h})$ & 70 & 12.98 & 10.00 & 15.50 & 5.50 & 1.28 & 1.13 & -0.12 & -0.12 \\
\hline $\mathrm{t}_{\mathrm{an}}(\mathrm{s})$ & 70 & 283.02 & 150.00 & 390.00 & 240.00 & 2675.45 & 51.72 & -0.03 & -0.49 \\
\hline$D s_{\text {tot }}(m)$ & 70 & 1232.90 & 583.31 & 1824.92 & 1241.61 & 77444.21 & 278.28 & 0.13 & -0.62 \\
\hline
\end{tabular}

Note. $\mathrm{VO}_{2 \max }$ - maximum absolute oxygen uptake; $\mathrm{RVO}_{2 \max }$ - maximum relative oxygen uptake; $\mathrm{v}_{\max }-$ maximum speed on the treadmill; $\mathrm{v}_{\mathrm{AnT}}$ - running speed at the anaerobic threshold; $\mathrm{t}_{\mathrm{an}}$ - time in the anaerobic zone; $\mathrm{ds}_{\mathrm{tot}}$ - distance covered in the anaerobic zone.

Table 2. Central and dispersive parameters of the variables and the significance of differences between point guards (PG); shooting guards (SG)/small forwards (SF); and power forwards (PF)/centers (C) in basketball

\begin{tabular}{|c|c|c|c|c|}
\hline Test & $\begin{array}{l}P G(n=20) \\
\text { Mean } \pm S D \\
\text { Min-max }\end{array}$ & $\begin{array}{c}\text { SG, SF }(n=26) \\
\text { Mean } \pm S D \\
\text { Min-max }\end{array}$ & $\begin{array}{c}P F, C(n=24) \\
\text { Mean } \pm S D \\
\text { Min-max }\end{array}$ & $p$ \\
\hline $\mathrm{VO}_{2 \max }(1 / \min )$ & $\begin{array}{c}4.7 \pm 0.6 \\
3.92-6.06\end{array}$ & $\begin{array}{c}5.01 \pm 0.6 \\
3.99-5.87\end{array}$ & $\begin{array}{l}5.55 \pm 0.6 \\
4.62-6.82\end{array}$ & 0.00 \\
\hline $\mathrm{RVO}_{2 \max }(\mathrm{ml} / \mathrm{kg} / \mathrm{min})$ & $\begin{array}{c}56.7 \pm 4.9 \\
47.90-65.10\end{array}$ & $\begin{array}{c}55.0 \pm 4.7 \\
44.90-65.20\end{array}$ & $\begin{array}{c}54.9 \pm 4.9 \\
48.50-65.20\end{array}$ & 0.39 \\
\hline $\mathrm{v}_{\max }(\mathrm{km} / \mathrm{h})$ & $\begin{array}{c}18.0 \pm 1.5 \\
16.00-21.00\end{array}$ & $\begin{array}{c}17.7 \pm 1.5 \\
15.00-20.00\end{array}$ & $\begin{array}{c}17.4 \pm 1.4 \\
14.00-20.00\end{array}$ & 0.34 \\
\hline $\mathrm{v}_{\text {AnT }}(\mathrm{km} / \mathrm{h})$ & $\begin{array}{c}13.3 \pm 1.1 \\
11.50-15.50\end{array}$ & $\begin{array}{c}13.0 \pm 1.2 \\
10.00-14.50\end{array}$ & $\begin{array}{c}12.6 \pm 1.0 \\
10.50-14.50\end{array}$ & 0.11 \\
\hline $\mathrm{t}_{\mathrm{an}}(\mathrm{s})$ & $\begin{array}{l}282.0 \pm 60.3 \\
180.0-390.0\end{array}$ & $\begin{array}{c}280.3 \pm 50.1 \\
150.0-360.0\end{array}$ & $\begin{array}{c}286.7 \pm 47.5 \\
210.0-372.0\end{array}$ & 0.89 \\
\hline$D s_{\text {tot }}(m)$ & $\begin{array}{l}1255.7 \pm 312.8 \\
737.4-1824.9\end{array}$ & $\begin{array}{l}1222.7 \pm 275.1 \\
583.3-1724.9\end{array}$ & $\begin{array}{l}1224.8 \pm 261.8 \\
729.1-1720.4\end{array}$ & 0.92 \\
\hline
\end{tabular}

Note. $\mathrm{VO}_{2 \max }$ - maximum absolute oxygen uptake; $\mathrm{RVO}_{2 \max }$ - maximum relative oxygen uptake; $\mathrm{v}_{\max }$ - maximum speed on the treadmill; $\mathrm{V}_{\mathrm{AnT}}-$ running speed at the anaerobic threshold; $\mathrm{t}_{\mathrm{an}}$ - time in the anaerobic zone; $\mathrm{ds}_{\mathrm{tot}}$ - distance covered in the anaerobic zone.

\begin{tabular}{lccccc}
\hline $\mathrm{VO}_{2 \max }$ & $\mathrm{SS}$ & $\begin{array}{c}\text { Degree } \\
\text { of } \\
\text { freedom }\end{array}$ & $\mathrm{MS}$ & $\mathrm{F}$ & $\mathrm{p}$ \\
\hline Intercept & 1842.002 & 1 & 1842.002 & 5443.802 & 0.00 \\
Position & 8.468 & 2 & 4.234 & 12.514 & 0.00 \\
Error & 23.686 & 70 & 0.338 & & \\
$\mathrm{VO}_{2 \max }$ & Position & $\{1\}$ & $\{2\}$ & $\{3\}$ & \\
\hline 1 & $\mathrm{~K}-1$ & & 0.26 & 0.00 & \\
2 & $\mathrm{~K}-2 \& 3$ & 0.26 & & 0.00 & \\
3 & $\mathrm{~K}-4 \& 5$ & 0.00 & 0.00 & & \\
\hline
\end{tabular}

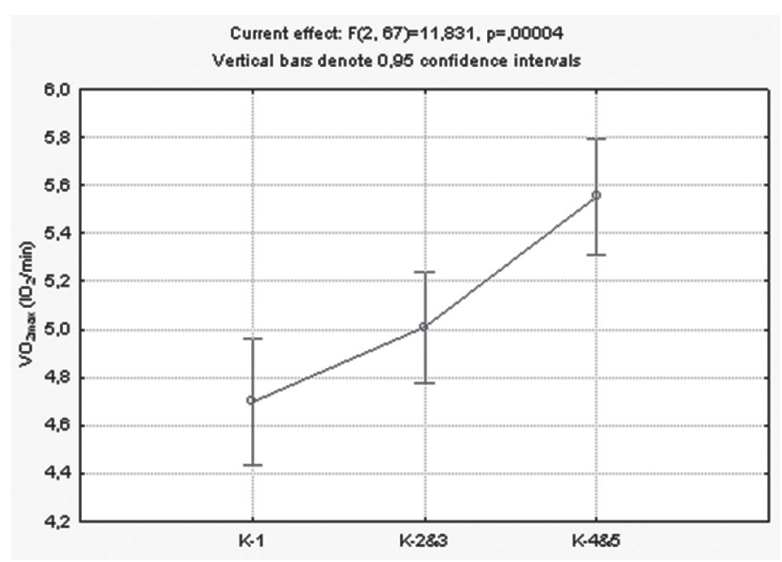

Table 3. and Figure 1. Average absolute maximum oxygen uptake $\left(V_{2 m a x} ; l /\right.$ min) for point guards (K1), guards and small forwards (K2\&3), power forwards and centers (K4\&5). 
$1 / \mathrm{min})$; and power forwards and centers $(5.55 \pm 0.6$ $1 / \mathrm{min}$ ). Results showed a statistically significant difference between the group of point guards (group 1) and shooting guards and small forwards (group 2), on the one hand, and centers and power forwards (group 3) in the variable average absolute maximum oxygen uptake $\left(\mathrm{VO}_{2 \max } ; 1 / \mathrm{min}\right)$.

Table 4 and Figure 2 display the results of relative maximum oxygen uptake for point guards
$(56.7 \pm 4.9 \mathrm{ml} / \mathrm{kg} / \mathrm{min})$; shooting guards and small forwards $(55.0 \pm 4.7 \mathrm{ml} / \mathrm{kg} / \mathrm{min})$; and power forwards and centers $(54.9 \pm 4.9 \mathrm{ml} / \mathrm{kg} / \mathrm{min})$. Results showed that there was no statistically significant difference between the groups in average relative maximum oxygen uptake $\left(\mathrm{RVO}_{2 \max } ; 1 / \mathrm{min}\right)$.

Table 5 and Figure 3 exhibit the results of maximum speed on the treadmill for point guards $(18.0 \pm 1.5 \mathrm{~km} / \mathrm{h})$; shooting guards and small

\begin{tabular}{lccccc}
\hline $\mathrm{RVO}_{2 \text { max }}$ & SS & $\begin{array}{c}\text { Degree } \\
\text { of } \\
\text { freedom }\end{array}$ & MS & $\mathrm{F}$ & $\mathrm{p}$ \\
\hline Intercept & 221971.3 & 1 & 221971.3 & 9168.014 & 0.00 \\
Position & 36.8 & 2 & 18.4 & 0.759 & 0.39 \\
Error & 1694.8 & 70 & 24.2 & & \\
\hline $\mathrm{RVO}_{2 \max }$ & Position & $\{1\}$ & $\{2\}$ & $\{3\}$ & \\
\hline 1 & $\mathrm{~K}-1$ & & 0.74 & 0.63 & \\
\hline 2 & $\mathrm{~K}-2 \& 3$ & 0.74 & & 1.00 & \\
3 & $\mathrm{~K}-4 \& 5$ & 0.63 & 1.00 & & \\
\hline
\end{tabular}

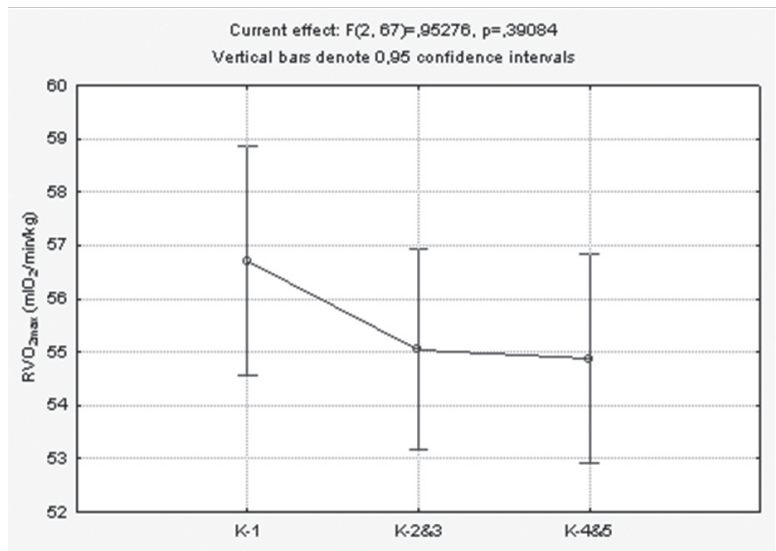

Table 4. and Figure 2. Average relative maximum oxygen uptake $\left(\mathrm{RVO}_{2 \max }, \mathrm{l} / \mathrm{min}\right)$ for point guards (K1), guards and small forwards (K2\&3), power forwards and centers (K4\&5).

\begin{tabular}{lccccc}
\hline $\mathrm{V}_{\max }$ & $\mathrm{SS}$ & $\begin{array}{c}\text { Degree } \\
\text { of } \\
\text { freedom }\end{array}$ & MS & $\mathrm{F}$ & $\mathrm{p}$ \\
\hline Intercept & 22515.18 & 1 & 22515.18 & 10477.66 & 0.00 \\
Position & 4.64 & 2 & 2.32 & 1.08 & 0.34 \\
Error & 150.42 & 70 & 2.15 & & \\
\hline $\mathrm{V}_{\max }$ & Pozicija & $\{1\}$ & $\{2\}$ & $\{3\}$ & \\
\hline 1 & $\mathrm{~K}-1$ & & 1,00 & 0,47 & \\
\hline 2 & $\mathrm{~K}-2 \& 3$ & 1,00 & & 0,93 & \\
\hline 3 & $\mathrm{~K}-4 \& 5$ & 0,47 & 0,93 & & \\
\hline
\end{tabular}

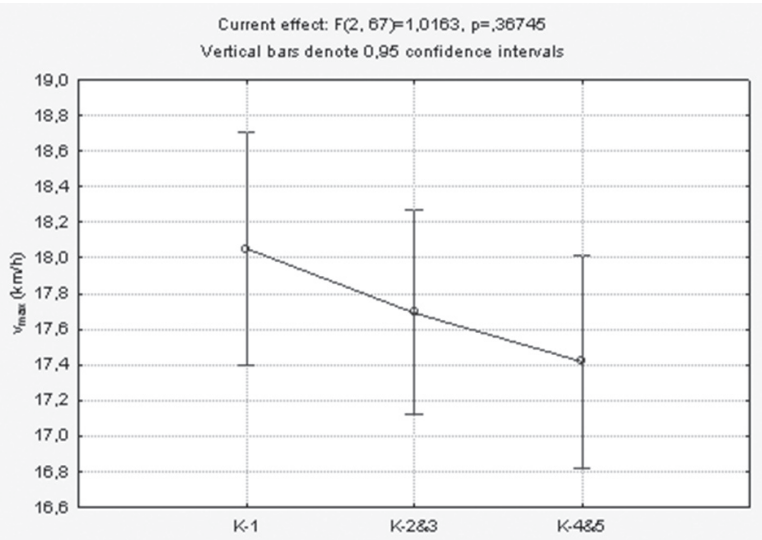

Table 5. and Figure 3. Average maximum speed on the treadmill $\left(V_{\max } ; \mathrm{km} / \mathrm{h}\right)$ for point guards $(K 1)$, guards and small forwards (K2\&3), power forwards and centers (K4\&5).

\begin{tabular}{lccccc}
\hline $\mathrm{V}_{\mathrm{AnP}}$ & $\mathrm{SS}$ & $\begin{array}{c}\text { Degree } \\
\text { of } \\
\text { freedom }\end{array}$ & $\mathrm{MS}$ & $\mathrm{F}$ & $\mathrm{p}$ \\
\hline Intercept & 12145.51 & 1 & 12145.51 & 9427.862 & 0.00 \\
Position & 6.19 & 2 & 3.10 & 2.404 & 0.11 \\
Error & 90.18 & 70 & 1.29 & & \\
\hline $\mathrm{V}_{\text {AnP }}$ & Pozicija & $\{1\}$ & $\{2\}$ & $\{3\}$ & \\
\hline 1 & $\mathrm{~K}-1$ & & 0.96 & 0.11 & \\
2 & $\mathrm{~K}-2 \& 3$ & 0.96 & & 0.68 & \\
3 & $\mathrm{~K}-4 \& 5$ & 0.11 & 0.68 & & \\
\hline
\end{tabular}

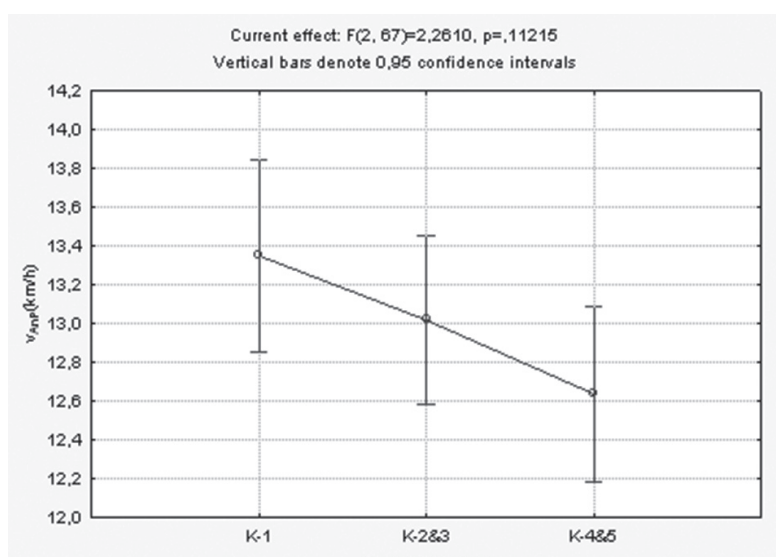

Table 6. and Figure 4. Average speed at the anaerobic threshold $\left(V_{A n} ; \mathrm{km} / \mathrm{h}\right)$ for point guards $(\mathrm{Kl})$, guards and small forwards (K2\&3), power forwards and centers (K4\&5). 


\begin{tabular}{lccccc}
\hline $\mathrm{t}_{\mathrm{an}}$ & $\mathrm{SS}$ & $\begin{array}{c}\text { Degree } \\
\text { of } \\
\text { freedom }\end{array}$ & $\mathrm{MS}$ & $\mathrm{F}$ & $\mathrm{p}$ \\
\hline Intercept & 5715143 & 1 & 5715143 & 2166.339 & 0.00 \\
Position & 561 & 2 & 281 & 0.106 & 0.89 \\
Error & 184671 & 70 & 2638 & & \\
\hline $\mathrm{t}_{\mathrm{an}}$ & Pozicija & $\{1\}$ & $\{2\}$ & $\{3\}$ & \\
\hline 1 & $\mathrm{~K}-1$ & & 1.00 & 1.00 & \\
\hline 2 & $\mathrm{~K}-2 \& 3$ & 1.00 & & 1.00 & \\
\hline 3 & $\mathrm{~K}-4 \& 5$ & 1.00 & 1.00 & & \\
\hline
\end{tabular}

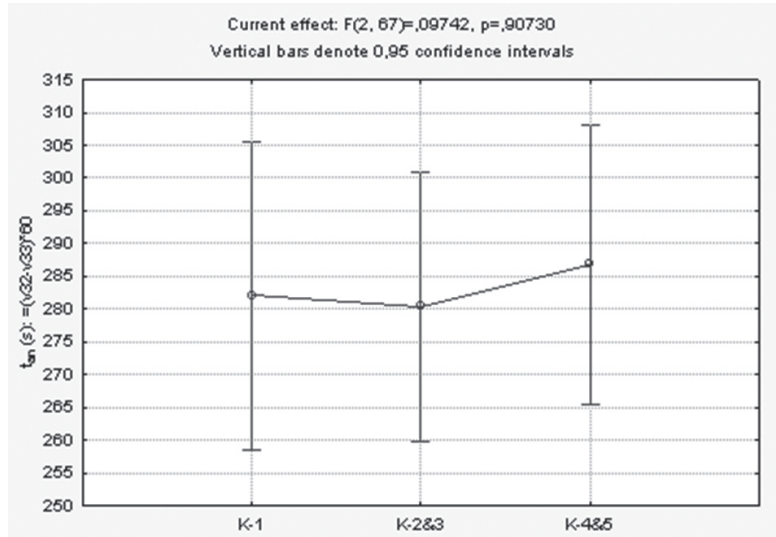

Table 7. and Figure 5. Average time in the anaerobic zone $\left(t_{\text {an }} ; s\right)$ for point guards $(K 1)$, guards and small forwards (K2\&3), power forwards and centers (K4\&5).

\begin{tabular}{lccccc}
\hline $\mathrm{ds}_{\mathrm{uk}}$ & $\mathrm{SS}$ & $\begin{array}{c}\text { Degree } \\
\text { of } \\
\text { freedom }\end{array}$ & MS & $\mathrm{F}$ & $\mathrm{p}$ \\
\hline Intercept & 10926615 & 1 & 10926615 & 1429.49 & 0.00 \\
Position & 11254 & 2 & 5627 & 0.074 & 0.92 \\
Error & 5350597 & 70 & 76437 & & \\
\hline $\mathrm{ds}_{\mathrm{uk}}$ & Pozicija & $\{1\}$ & $\{2\}$ & $\{3\}$ & \\
\hline 1 & $\mathrm{~K}-1$ & & 1.00 & 1.00 & \\
\hline 2 & $\mathrm{~K}-2 \& 3$ & 1.00 & & 1.00 & \\
\hline 3 & $\mathrm{~K}-4 \& 5$ & 1.00 & 1.00 & & \\
\hline
\end{tabular}

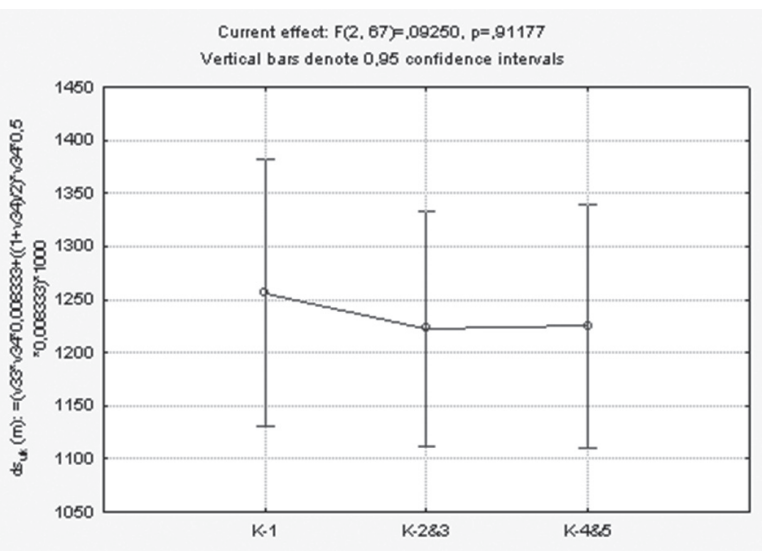

Table 8. and Figure 6. Average distance covered in the anaerobic zone $\left(d s_{\text {tota }} ; m\right)$ for point guards (K1), guards and small forwards (K2\&3), power forwards and centers (K4\&5).

forwards $(17.7 \pm 1.5 \mathrm{~km} / \mathrm{h})$; and power forwards and centers $(17.4 \pm 1.4 \mathrm{~km} / \mathrm{h})$. Results showed that there was no statistically significant difference between the groups in average maximum speed on the tread$\operatorname{mill}(\operatorname{Vmax} ; \mathrm{km} / \mathrm{h})$

Table 6 and Figure 4 display the results of average speed at the anaerobic threshold for point guards $(13.3 \pm 1.1 \mathrm{~km} / \mathrm{h})$; shooting guards and small forwards $(13.0 \pm 1.2 \mathrm{~km} / \mathrm{h})$; and power forwards and centers $(12.6 \pm 1.0 \mathrm{~km} / \mathrm{h})$. Results showed that there was no statistically significant difference between the groups in average speed at the anaerobic threshold $\left(\mathrm{V}_{\mathrm{AnT}} ; \mathrm{km} / \mathrm{h}\right)$.

\section{Analysis of differences in the variables assessing anaerobic capacities of players in different play positions}

Table 7 and Figure 5 display the results of average time in the anaerobic zone point guards; shooting guards and small forwards; and power forwards and centers of $280.3 \pm 50.1 \mathrm{~s}, 282.0 \pm 60.3$ $\mathrm{s}$, and $286.7 \pm 47.5 \mathrm{~s}$, respectively. Results showed that there was no statistically significant difference between the groups in average time spent in the anaerobic zone $\left(\mathrm{t}_{\mathrm{an}} ; \mathrm{s}\right)$.
Table 8 and Figure 6 present the results of average distance covered in the anaerobic zone for point guards (1255.7 $\pm 312.8 \mathrm{~m})$; shooting guards and small forwards $(1222.7 \pm 275.1 \mathrm{~m})$; and power forwards and centers (1224.8 $\pm 261.8 \mathrm{~m})$. Results showed that there was no statistically significant difference between the groups in average distance covered in the anaerobic zone $\left(\mathrm{ds}_{\text {tota }} ; \mathrm{m}\right)$.

\section{Discussion and conclusion}

This study was conducted with the aim of analyzing the differences in aerobic and anaerobic parameters of top basketball players in different play positions. The subject sample consisted of 70 basketball players from the Croatian Division I basketball league. Statistically significant differences were found among basketball players in different play positions in parameters of $\mathrm{VO}_{2 \max }$, while the analysis of the differences in other variables showed no statistically significant differences.

It is well known that a better aerobic capacity provides faster recovery after short high-intensity actions (Hoffman, Epstein, Einbinder \& Weinstein, 1999; Reilly \& Gilbourne, 2003; Spencer, Bishop, 
Dawson, \& Goodman, 2005). For that reason, aerobic capacity is of vital importance to basketball players. Analysis of variables assessing aerobic capacity among play positions showed a significant difference for the $\mathrm{VO}_{2 \max }$ variable. In that variable, the difference was found when comparing power forwards and centers to point guards as well as shooting guards and small forwards. The differences could be explained with the phenomenon of positive correlation between body mass and $\mathrm{VO}_{2 \max }$ $(\mathrm{p}=.00, \mathrm{r}=0.61)$ because basketball is a sport where players differ significantly in body type.

The $\mathrm{RVO}_{2 \max }$ average values for point guards, shooting guards/small forwards, guards; shooting guards and small forwards; and power forwards and centers $(56.7,55.0$ and $54.8 \mathrm{ml} / \mathrm{kg} / \mathrm{min}$, respectively) are consistent with the studies by Latin, Berg, and Baechle (1994), Sallet, Perrier, Ferret, Vitelli, and Baverel (2005), and Abdelkrim et al. (2010). When compared to the studies by Parr, Wilmore, Hoover, Bachman, and Kerlan (1978), Ostojić et al. (2006), and Cormery et al. (2008), the results of this study show even slightly higher scores. Furthermore, the fact that statistically significant difference in the variable $\mathrm{RVO}_{2 \max }$ was not found between the players in different play positions confirms some of the conducted studies (Latin, et al., 1994; Sallet, et al., 2005), but contradicts the results of other studies (Cormery, et al., 2008; Ostojić, et al., 2006) where significant differences were found between different play positions saying that point guards and shooting guards scored higher than forwards and centers. The homogenized values of $\mathrm{RVO}_{2 \max }$ between play positions could be explained by the demands of basketball game.

Some differences among the play positions in the variable of the distance covered with different intensities during a game (Abdelkrim, et al., 2007; McInnes, et al., 1995), together with the differences in specific offensive and defensive actions (Abdelkrim et al., 2007; Cuzzolin, 2005) obviously are not pronounced enough to make the difference in $\mathrm{RVO}_{2 \max }$, which is explained through a modern concept of physiologically very demanding basketball game regardless of the position and role of a player on the court. Modern basketball demands high aerobic capacity, which enhances the recovery ability after short high-intensity actions, being a very important part of performance in all team sports (Reilly, et al., 2003; Spencer, et al., 2005). Furthermore, optimal $\mathrm{RVO}_{2 \max }$ level enables the implementation of very demanding training programs of 15-20 hours/week with average duration of 90-120 minutes.

The results of this paper correspond to the study of Cormery et al. (2008) where statistically significant differences were not found among different play position for the $\% \mathrm{VO}_{2}$ variable. The maximal speed reached $\left(\mathrm{v}_{\max }\right)$ and running speed at the anaer- obic threshold $\left(\mathrm{v}_{\mathrm{AnT}}\right)$ present very important data for training process programming, especially the variable $\mathrm{v}_{\mathrm{AnT}}$, which, in combination with $\mathrm{FS}_{\mathrm{AnT}}$, enables a precise design of training protocols for the improvement of aerobic and anaerobic fitness level. Even though the point guards achieved better results in $\mathrm{v}_{\max }$ and $\mathrm{v}_{\mathrm{AnT}}$ when compared to the other play positions in basketball, statistical difference was not found.

The analysis of differences between the variables assessing anaerobic capacities did not show any statistically significant difference for the players in different play positions. Even though the differences exist between positions in some specific tasks (Abdelkrim, et al., 2007; Cuzzolin, 2005; Miller \& Bartlett, 1994), the distance covered during a game (Abdelkrim, et al., 2007), the number of different moves during a game (Abdelkrim et al., 2007; Cuzzolin, 2005), and overall percentage of time spent in a high-intensity zone (Abdelkrim, et al., 2007; Miller \& Bartlett, 1994), they are not discriminative enough to produce significant differences in anaerobic capacities. In basketball, point guards play most with the ball, but shooting guards and small forwards participate in transitional offense plays, whereas power forwards and centers participate in specific tasks where contact between players often occur (Miller \& Bartlett, 1994), and by that the players kind of compensate for the total distance covered during a game (Abdelkrim, et al., 2007).

Considering the fact that an average offense play time is 7-18 seconds, where the positional offense play takes 7-18 seconds ( $75 \%$ of all offensive time), while the transitional offense play lasts only 4-6 seconds (Tavares \& Gomes, 2003), the authors conclude that, because of a very dynamic nature of both the positional and transitional play, there is a significant need for players' high anaerobic capacities in every play position. Furthermore, during a game, every team nowadays performs 180-200 offense plays on average with power forwards and centers also playing important roles in transitional actions. Besides, many offensive and defensive actions demand a high level of on-court agility from power forwards and centers. Knowing the fact that basketball players should develop and maintain high anaerobic endurance, it is quite demanding for them to play 60-70 games per season of eight months. Based on the aforementioned facts, coaches implement the strategy where rarely any player on the team plays more than 30 minutes per game; in season 2010/2011 in the Spanish Division I basketball league only four players played more than 30 minutes per game on average (Vaquera, et al., 2006).

Croatian basketball players and their aerobic and anaerobic fitness are in the level with the other professional players from Serbia and France (Cormery, et al., 2008; Ostojić, et al., 2006). As an 
example, point guard R. U. $\left(\mathrm{VO}_{2 \max } 64 \mathrm{mlO}_{2} / \mathrm{kg} /\right.$ min, $\left.\mathrm{ds}_{\text {tot }} 1624 \mathrm{~m}\right)$ and center A.T. $\left(\mathrm{VO}_{2 \max } 59 \mathrm{mlO}_{2} /\right.$ $\mathrm{kg} / \mathrm{min}, \mathrm{ds}_{\text {tot }} 1329 \mathrm{~m}$ ) have an appropriate level of work capacities to compete in the highest ranked European leagues. The analysis of cardio-pulmonary functioning provides useful information about the structure and predominance of energy processes within different sport disciplines. In order to conduct a precise analysis of energy demands for a given team sport, it is important to investigate all the activities, especially the high-intensity actions. The findings of the present study suggest that parameters of aerobic and anaerobic power and capacities have small discriminative power to differentiate among players with different positional roles. Nevertheless, certain numerical differences must be highlighted: guards and forwards manifested a slightly better aerobic capacity, which provided them with a shorter recovery time and ability to efficiently repeat high-intensity basketball-specific activities. Also, the Croatian players in all three main positions had high values of anaerobic capacities, equipping them with the ability to play powerfully with substantial contact.

This study provided useful information on the differences among basketball players on different basketball positions demonstrating that no significant difference but one existed in the parameters of aerobic and anaerobic fitness profiles among posi- tions, which is similar to the studies by Cormery et al. (2008), Latin et al. (1994), and Sallet et al. (2005). The number of subjects was compatible with the purpose of the study and the defined hypotheses. However, a larger sample of subjects of different age and competition level groups should be considered in future studies to get a better idea of the differences between different groups of players. Also, it would be important to further examine positions in basketball in more detail and to use specific tests for the assessment of motor and energy supplying abilities with a view to getting a deeper insight into the specific requirements of each play position in basketball.

Knowing the status of players' energy capacities is helpful for the coaches to have the best information for optimal planning and programming of practices, which is a practical application of this study. Also, knowing the differences in energy capacities among the play positions together with the GPS game analysis data provides the best information for optimal planning of practices. During training sessions, coaches can use this information to create more individualized strength and conditioning programs for different positional roles. This will enable them to maximize players' physiological potential, which is an integral part of playing basketball.

\section{References}

Abdelkrim, N.B., El Fazaa, S., \& El Ati, J. (2007). Time-motion analysis and physiological data of elite under-19-year old basketball players during competition. British Journal of Sports Medicine, 41(2), 69-75.

Abdelkrim, N., Chaouachi, A., Chamari, K., Chtara, M., \& Castagna, C. (2010). Positional role and competitive-level differences in elite-level men's basketball players. Journal of Strength and Conditioning Research, 24(5), 13461355.

Cormery, B., Marcil M., \& Bouvard, M. (2008). Rule change incidence on physiological characteristics of elite basketball players: A 10-year-period investigation. British Journal of Sports Medicine, 42(1), 25-30.

Cuzzolin, F. (2005). I movimenti di torsione nella pallacanestro: Analisi e proposte di lavoro. [Torsion movements in basketball. Analysis and recommendations. In Italian.] Retrieved from www.preparazioneatletica.it on December $10,2010$.

Hoffman, J., Epstein, S., Einbinder, M., \& Weinstein, Y. (1999). The influence of aerobic capacity on anaerobic performance and recovery indices in basketball players. Journal of Strength and Conditioning Research, 13(4), 407-411.

Latin, R., Berg, K., \& Baechle, T. (1994). Physical and performance characteristics of division I male basketball players. Journal of Strength and Conditioning Research, 8(4), 214-218.

McInnes, S.E., Carlson, J.S., Jones, C.J., \& McKenna, M.J. (1995). The physiological load imposed on basketball players during competition. Journal of Sport Sciences, 13 (5), 387-397.

Miller, S., \& Bartlett, R. (1994). Notational analysis of the physical demands. Journal of Sports Sciences, 12, 181.

Ostojić, S., Mazić, S., \& Đikić, N. (2006). Profiling in basketball: Physical and physiological characteristics of elite players. Journal of Strength and Conditioning Research, 20(4), 740-744.

Parr, R., Wilmore, J., Hoover, R., Bachman, D., \& Kerlan, R. (1978). Professional basketball players: Athletic profile. The Physician and Sportsmedicine, 6(4), 78-79. 
Read, P.J., Hughes, J., Stewart, P., Chavda, S., Bishop, C., Edwards, M., \& Turner, A.T. (2014). A needs analysis and field-based testing battery for basketball. Strength and Conditioning Journal, 36(3), 13-20

Refoyo, I. (2001). La desision tactica de juego y su relacion con la respuesta biologica de los jugadores. Una aplicacion al baloncesto como deporte de equipo. [Tactical decision making and its relation to biological response of players. Application to basketball. In Spanish.] (Doctoral dissertation, Universidad Complutense de Madrid).

Reilly, T., \& Gilbourne, D. (2003). Science and football: A review of applied research in the football codes. Journal of Sport Science, 21, 693-705.

Sallet, P., Perrier, D., Ferret, J.M., Vitelli, V., \& Baverel, G. (2005). Physiological differences in professional basketball players as a function of playing position and level of play. Journal of Sports Medicine and Physical Fitness, 45(3), 291-297.

Spencer, M., Bishop, D., Dawson, B., \& Goodman, D. (2005). Physiological and metabolic responses of repeated-sprint activities. Sports Medicine, 35(12), 1025-1044.

Tavares, F., \& Gomes N. (2003). The offensive process in basketball - A study in high performance junior teams. International Journal of Performance Analysis in Sport, 3(1), 34-39.

Vaquera, A., Refoyo, I., Villa, J., Calleja, J., Rodriguez-Marroyo, J., Garcia-Lopez, J., \& Sampedro, J. (2008). Heart rate response to game-play in professional basketball players. Journal of Human Sport and Exercise, 3(1), 1-9.

Submitted: September 25, 2019

Accepted: November 26, 2019

Published Online First: December, 19, 2019

Correspondence to:

Marin Dadić, M.Sc.

Faculty of Kinesiology, University of Zagreb, Croatia

Email: marin.dadic@yahoo.com 